\title{
Perceived Barriers And Facilitators To Access Mental Health Services Among Pakistani Adolescents
}

\author{
Hina Nizam* and Saima Masoom Ali \\ Department of Psychology, University of Karachi, Karachi, Pakistan
}

Received: September 15, 2021 Accepted: December 30, 2021 DOI: $10.46568 /$ bios.v2i2.46

\begin{abstract}
Introduction: Mental health problems have a high rate of prevalence among adolescents in Pakistan, however, the tendency to access mental health professionals for the treatment has been low due to some barriers. The current review focuses on those barriers and identifies the relevant facilitators in reducing the barriers to enhance the well-being of adolescents. Methodology: By considering the objective of the study, the adolescents whose age ranged between 10-19 years were included, the research work done during 2012-2018 was accessed through Pub Med, Science Direct, Google Scholar and SAGE articles. The key terms mental health services, adolescents, barriers, facilitators were used to locate the articles. Result: Most prevailing barriers were found as stigmatizing belief, lack of awareness, preference for other sources and scarcity of mental health services. Social support from significant others, finding an expression for the problems, customized mental health advertisements, increased awareness about mental health and providing online services for mental health problems can facilitate for reducing reluctance in adolescents for accessing mental health help services. Discussion: Mental health awareness programs can facilitate in reducing the above-mentioned barriers. This review can make it easier to lower down the perceived barriers among adolescents which consequently encourage them to seek help they require. Recommendations for future research are further discussed.
\end{abstract}

Keywords: Mental health services, Adolescents, Barriers, Facilitators

*Correspondence: Hina Nizam, Department of Psychology, University of Karachi, Karachi, Pakistan, Tel: +92-336-2462380 Email: hinaameenmoosa@gmail.com

\section{Introduction}

According to the definition proposed by The World Health Organization (WHO, 2013), Adolescents are individuals of ages from 10 to 19 years. Adolescence is characterized by a transitional period with a rapid change physiologically, sexually and emotionally $[1,2]$. Due to having this transition adolescents are more prone towards mental health problems such as psychological stress, depression and substance abuse as compared to old adults [3-6]. Surprisingly, despite having the higher rate of mental health problems but accessing mental health help to treat the problems is lower [7]. It is declared that 23 percent of population of Pakistan embodies adolescents whose age ranges between 10 to 19 years [8]. This age group has a greater predisposition to a variety of risks such as sexual violence, substance abuse, unintended teen pregnancy, self-harm and attempts to suicide [6, 9-11].

The World Health Organization (WHO) came up with a comprehensive concept of Mental Health which states that Mental Health is not only the absence of mental disorder rather it is a state of well-being due to which an individual faces the stressors of life by utilizing one's full potentials and capabilities with resilience and contributes in a good manner to the society [12].

The percentage of people who do not receive treatment but need help for mental issues is referred as treatment gap which lies between $44 \%-70 \%$ in developed countries and with an alarming rate of $90 \%$ in developing countries [13]. The treatment gap raises many factors that causes hindrance in accessing mental health help. Reduction in this gap can only be possible by addressing the barriers and facilitators to access mental health help. World Health Organization declares that more than $56 \%$ people suffering from depression and $78 \%$ people suffering from alcohol abuse 
have been untreated due to the barriers. A mental health survey reported extremely perilous results that out of $52.6 \%$ of individuals living in low income countries having MDD but only 20.5 $\%$ out of all patients receiving minimal treatment for their disorder [14].

Mental health problems have been increasingly prevailing among developing countries as well as developed countries. However, prevalence in developing countries is higher than developed countries which accounted for $85 \%$ and $50 \%$ respectively [15]. Globally, out of overall disease burden, mental health problems such as depression, substance use disorders, personality disorders and other mental and neurological disorders embodies $13 \%$ which implies that patients suffering with mental health problems globally are 450 million [16].

The high susceptibility of individual to develop mental health problems but refrain from getting any kind of formal help such as from mental health counselors and any kind of informal help from family friends etc. There is an emerging discussion of seeking self-help to utilize computer mediated communication technologies. This review paper addresses those perceived barriers and facilitators among adolescents by using both qualitative and quantitative published researches and articles. Recognition of the barriers will help identify ways to overcome them and reduce the treatment gap.

\section{Literature Review}

Mental health help seeking refers to looking around to communicate the difficulties to others for seeking assistance and further treatment options [16]. Extensive literature on mental health help seeking does not provide a consensus on a definition on help seeking. People who suffer from mental health problems can seek help from three sources. First, Formal help that is from a psychologist, psychiatrist and other professionals dealing with mental health problems. Second, Informal help such as help from family, friends etc. While mental health problems are more common among young adults but approaching to help seeking for solutions remains at a drastically low percentage. To investigate the mental health issues and reluctant attitude to access mental health services, an online survey was developed with open ended question to examine the reasons for the reluctance in accessing help for treatment of the mental health problem. After a complete analysis, $35 \%$ of the participants claimed about their psychological distress but did not access help due to perceived barriers such as stigmatizing beliefs, low perceived needs, reliance on self, difficulty accessing help, fear of negative outcome, difficulty identifying or expressing concerns [18]. It has been reported that hundreds of millions of people receiving primary care are susceptible to mental illnesses which are diagnosable. As per the estimate the percentage of people was found to be 60 percent who attend clinics for primary care but suffering from depression, schizophrenia, substance abuse and dementia [19]. In Pakistan, people with mild to moderate level of mental illness are between 10-16\%.Socio-cultural and economic factors play a role for this prevailing figure in Pakistan [20].

Government of Pakistan allocates a negligible amount of total GDP in health sector which is only $0.9 \%$. equals approximately $\$ 9.31$ per unit population annually [21] which obstruct poor people to access mental health services. Financial barriers hinders in promoting and facilitating people in regard with mental health services. The total mental health budget merely stands at the $0.04 \%$ of the total health budget in Pakistan [22]. According to report of World Bank, Pakistan's poverty rate was $21.9 \%$ in 2018 which results in lack of resources towards accessing mental health professionals.

Adolescent period is a crucial period as there is greater chance of bullying, either someone becomes bully or the victim of bullying, in both the cases, mental health issues arise among adolescents which need to be addressed. A study conducted in Pakistan, declared a higher percentage $(41 \%)$ of national sample $(n=4977)$ found to be bullying victim [23]. 
Barriers in accessing mental health help identified by most of the research include stigmatizing beliefs [24-27], lack of Awareness [28-31], preference for other sources[28-32] and scarcity of mental health services [13, 33-37].

This review paper is an attempt to fill the gap which is evident in available literature on this topic. This important topic needs to have attention for research scholars with reference to Pakistani adolescents. Adolescence is a period where required help can develop adolescents into healthy adults. Youth is a period of sensitive risk for mental health conditions, with half of all lifetime mental health disorder developing before the age of 14 years. In our Pakistani society access to mental health services for an adolescent is a challenge, being an adult when individual realize about the problems they suffer they avail services but as an adolescent individual has to rely on parents. There is a scarcity of empirical evidence on access mental health services by adolescents specifically in Pakistan ${ }^{17}$. Inculcating insight in parents that their child needs mental health services is not an easy task. There is a need to raise public awareness of the importance of seeking mental health services as well as for designing, assessing as well as executing strategies to reduce self and social stigma related to mental health problems.

\section{Methodology}

This review of literature includes only four databases Pub Med, Science Direct, Google Scholar, SAGE to locate the articles on this topic. Limits concerning the year of publication were set for the database search which includes all relevant published articles during the years 2012 to 2018 . All the articles were located by specific key terms as " mental health services"," adolescents", "barriers", "facilitators". No limits for the demographic characteristics of participants were set except the age which was between 10 to 19 years. All articles were excluded which were not having this particular age group as adolescents. All study designs and all kinds of mental illnesses mentioning the search terms were covered in this review article.

\section{Results}

Table 1 Perceived Barriers in accessing Mental Health Services

\begin{tabular}{|c|c|}
\hline Barriers & Author/ Year \\
\hline Stigmatizing Belief & $\begin{array}{l}\text { 1. Sultan, S. Perceived public stigma and attitude towards seeking Psychological } \\
\text { help among Turkish and Pakistani people. Pak J Psychol. 2012; 43(1): 41-53. } \\
\text { 2. Ali A., Hassiotis A., Strydom A., King M. Self-stigma in people with } \\
\text { intellectual disabilities and courtesy stigma in family carers: A systematic } \\
\text { review. Research in Developmental Disabilities. 2012; } 33 \text { (6): } 2122-40 \text {. } \\
\text { 3. Gulliver A, Griffiths KM, Christensen H. Barriers and facilitators to mental } \\
\text { health help-seeking for young elite athletes: a qualitative study. BMC } \\
\text { Psychiatry. 2012: 12(1): } 157 \\
\text { 4. Clement S, Schauman O, Graham T, et al. What is the impact of mental health- } \\
\text { related stigma on help-seeking? A systematic review of quantitative and } \\
\text { qualitative studies. Psychol. Med. 2015; 45(1): 11-27. }\end{array}$ \\
\hline Lack & $\begin{array}{l}\text { 1. Ali, N., McLachlan, N., Kanwar, S., \& Randhawa, G. Pakistani young people's } \\
\text { views on barriers to accessing mental health services. Int. J. Cult. Ment. 2017; } \\
\text { 10(1): 33-43. doi:10.1080/17542863.2016.1248456 } \\
\text { 2. Ciftci, A., Jones, N., \& Corrigan, P. W. Mental health stigma in the Muslim } \\
\text { community. J. Muslim Ment. Health. 2012; 7(1): 17-32. } \\
\text { 3. Iftikhar B, Bashirullah N, Ishtiaq M, Subhan M, Khan SA. Perception and } \\
\text { attitude of adolescents regarding adolescence related health issues in Peshawar } \\
\text { Pakistan. J. Med. Sci. 2016; } 24 \text { (4): 241-46. } \\
\text { 4. Hussain SS; Khan M; Gul R; Asad N. Integration of mental health into primary } \\
\text { healthcare: perceptions of stakeholders in Pakistan. East Mediterr Health J. }\end{array}$ \\
\hline
\end{tabular}




\begin{tabular}{|c|c|}
\hline & 2018. 24(2):146-153. https://doi.org/10.26719/2018.24.2.146. \\
\hline $\begin{array}{l}\text { Preference for other } \\
\text { sources }\end{array}$ & $\begin{array}{l}\text { 1. Ali, Tahir \& Gul, Sana. Community Mental Health Services in Pakistan: } \\
\text { Review Study from Muslim World 2000-2015. PCH. Psychol. Comm. Health. } \\
\text { 2018; 7: 57-71. 10.5964/pch. v711.224. } \\
\text { 2. Ciftci, A., Jones, N., \& Corrigan, P. W. Mental health stigma in the Muslim } \\
\text { community. J. Muslim Ment. Health. 2012; 7(1): 17-32. } \\
\text { 3. Hussain SS; Khan M; Gul R; Asad N. Integration of mental health into primary } \\
\text { healthcare: perceptions of stakeholders in Pakistan. East Mediterr Health J. } \\
\text { 2018. 24(2):146-153. https://doi.org/10.26719/2018.24.2.146. }\end{array}$ \\
\hline $\begin{array}{l}\text { Scarcity of Mental } \\
\text { Health Services }\end{array}$ &  \\
\hline
\end{tabular}

Table summarizes the key perceived barriers addressed in different studies during 2012-1018.

\section{Discussion}

Mental health is an integral and vital component of health. Seeking help is vital to one's wellbeing and fundamental to getting one's life back on track. Besides, this being able to have access to mental health help is of utmost importance. Particularly, international researches have revealed that adolescents are very reluctant to seek mental health help. Adolescence is a crucial and transitional period from childhood to adulthood. Therefore, they are progressing through intense changes such as separation from parents, choosing careers, getting admission in colleges/universities, worrying about their future etc. Particularly, at this time young adults start making decisions regarding career, education, relationships that have lifelong effects. Nevertheless, this is also the most emotionally and psychologically taxing duration of an individual's life.

\section{Perceived Barriers to access Mental Health Services}

Following the analysis of the content collected through the databases, it was reported that stigmatizing beliefs, low perceived needs, self-reliance, perceived ineffectiveness of the treatment and fear of negative outcomes were the primary barriers that were faced among adolescents in accessing mental health services for their mental health issues.

\section{Stigmatizing belief}

Societies play a significant role in the mental health of a person. Thus, when a person realizes he needs to seek help, the most prominent obstacle in the way is society or people around that person. In addition to this, their reaction is what effects the most and creates the attached stigma to mental health issues. Generally, people have perceived stigmatized beliefs regarding mental health issues as society tries to hide it and turns the individuals into outcasts. Besides if the person 
even tries to seek outside help the family is offended that how could the individual discuss their problems and family's internal issues with an outsider.

A study conducted on perceived stigma and attitudes towards accessing for mental health services between Pakistani and Turkish students, findings revealed that Pakistani students were more reluctant in accessing mental health services than Turkish students due to having perceived stigma and negative attitude. Moreover, Pakistani female students were found to have more stigmatizing beliefs than Pakistani male students [24]. Similarly, thirty-seven studies examining selfstigmatizing beliefs in people with intellectual disability was reviewed in the review paper. This review paper mentioned that not only the individuals with the disorder were stigmatized but, people who were associated with them reported that they received a negative attitude towards them from the public [25]. In a similar fashion, stigma ranked as the fourth-highest factor in obstructing the path to help-seeking according to the systematic review of 144 quantitative and qualitative studies executed to investigate the impact of stigma on Mental Health help-seeking [27]. Likewise, another research on young adult athletes aged 16-24 years conducted to identify the barriers and facilitators for the mental health help-seeking. Outcomes of the research showed that stigma was one of the most potent factors that opposed mental health help-seeking [26].

\section{Lack of awareness}

Mental health problems are not same as physical illnesses and are not easily rectified by lay persons. Emotional pain is always underrated in reference to solution and does not get the attention of the sufferer due to lack of awareness. People in Pakistan are not well-informed about signs and symptoms of mental illness which ultimately restrain people from accessing mental health services in Pakistan. People specially youth usually prefer to visit to general physician for their mental health problems [30]. Religious barriers also contribute to the reluctance in accessing towards mental health professional. Specifically, in Pakistan, certain myths and stereotypical attitudes prevails perceiving the mental illness either a blessing from God or the punishment for the sins and people indulge more in religious activities and seek help from religious and spiritual leaders [28].

A study conducted in Peshawar, Pakistan with 429 adolescents age ranged from 11 to 19 years found poor level of awareness regarding Psychological health whereas excellent level of awareness related to physical, sexual and overall health were reported, although role of friends was found to be higher rather than role of family and institute to make them aware about health related issues. Moreover, adolescents belonging from private institutions were more aware regarding psychological health than those who belonged from Government institutions [29].

Lack of awareness among the community was considered a barrier. Participants in a study in Pakistan highlighted the fact that there were many misconceptions about mental disorders, and the acceptance level of being mentally-ill remains low in Pakistani Communities [31].

\section{Preference for other sources}

People use other sources to access the treatment of Mental Health issues specifically in Pakistan. Results from a literature review consisted of thirteen studies between 2000-2015 in Muslim countries declared that people first access to religious/ faith healers for the treatment of mental health issues [32]. Religious figures and faith healers have been the most convenient source in Muslim communities rather than accessing Mental Health professionals [28]. A study declared that existence of primary health care system is negligible therefore people consult their mental health issues to medically qualified GP, religious healers (maulvi, peer), Hakeems (Unani medicine), homeopaths and faith healers (Aamils) [31].

\section{Scarcity of mental health services}


With the reluctance in seeking help for mental health problems, there comes another significant factor which is also a barrier that hospitals providing mental health services and mental health professionals are insufficient in Pakistan. Pakistan is a highly populous country having one hundred and ninety million population. Only four psychiatrist hospitals with less than 3000 inpatients beds are available in country for a significant large number of people. As far as the number of mental health professionals are concerned, they are also insufficient as per the need of the large population of the country as in Pakistan's mental health sector, there are about 3,145 social workers [37].

According to World Health Organization, the number of psychiatrists and psychologists providing mental health services are 520 and 480 respectively whereas mental health social workers are around 600 in Pakistan [33]. During a community-based intervention program conducted in 15 Urban communities in Karachi, 624 inpatients units with 2 bed per one hundred thousand population were found [36]. Despite of having insufficient number of mental health professionals, most of the population will not have a chance to access mental health services within their lifetime. Except mental health is not always integrated with primary health care, the disorders would be unidentified [35].

In Pakistan, Prevalence of Psychiatric patients has been increasing but treatment facilities provided by Government of Pakistan is insufficient. Still the field of Mental Health is in its infancy. Only four Psychiatric hospitals are working for a population of 120 Million at Government level. However, significant number of Non-Government Organizations are actively participating for maintaining the well-being of mentally ill people and spreading awareness about mental health at community level [34].

\section{Perceived Facilitators to access Mental Health Services \\ Customized Mental Health Advertisement}

Advertisement is one of the most integral parts of an individual's day. Constantly an individual is bombarded with a lot of persuasive advertisement which greatly influences his/her decisions. Thus, this new era requires a more effective way to communicate about mental health issues and to introduce normalcy in the concept of mental health issues and remove stigmatizing and negative outcomes. As a result, it will promote help-seeking attitude and help the person to get over the barriers in order to get professional help regarding supposed mental health issues. Hence effective advertisement placed accordingly to the young adult's popular preferences such as during sports or video games or they can put it on websites that are frequently visited by young adults

\section{Increased Mental Health Literacy}

Mental Health Literacy (MHL) or awareness is the knowledge and beliefs about mental disorders which aid their recognition, management or prevention. Meaning that awareness should be spread among the masses regarding the basic symptoms of how to recognize and differentiate between them and realize the need to have treatment for them. Help-seeking is defined as searching for help from external sources to cope up from mental health issues. Furthermore, lower rates of mental health literacy results in the larger treatment gap, those large treatment gaps result in a high rate of mental disorder prevalence [39].

Teachers training program in school and colleges will facilitate to change the perception of Pakistani teachers about mental health. A training program was conducted in Pakistan in which teachers, head of schools, officers concerned to ministry of education and school counselors participated, the study was based on pre-post experimental design, results showed that participants scored better after training regarding the knowledge of mental health and reported that they can work better in their relevant fields to promote the mental health of students after training. 
Biosight 2021; 02(02): 4-12

Another study revealed similar results through a web-based social network game named as "Ching Ching story" which focused considerably on introducing mental health issues and its symptoms and problem-solving skills of young adults in a game like mode and it was noted that participants reported it was much easier to understand the mental health issues better and clearly through this method [40].

\section{Conclusion}

The significance of mental health and its help-seeking is universally accepted and cannot be denied. Consequently, there are some perceived barriers that create a treatment gap. In this case, stigmatizing beliefs, low perceived needs, self-reliance, the ineffectiveness of treatment and fear of negative outcomes are those perceived barriers. Besides this, some of the facilitators that lessen the treatment gap are understanding of mental health through targeted advertisement and other awareness programs which helps young adults overcome the reluctance to seek help regarding mental health issues.

\section{Limitations and Recommendations}

Limitations in the present review paper need to be considered. Firstly, the research method was not exhaustive only four key terms were used and only four databases were used to locate articles which might have missed relevant studies. Secondly, the barriers listed are few among the many faced by adolescents in Pakistan including religious, cultural and societal. Furthermore, succeeding researches should incorporate those barriers which obstruct the way to seek help specifically in Pakistan. In brief, this research deals with the key idea of the initial hindrance in seeking help future studies should be made on those individuals that leave an ongoing treatment provided by a formal mental health care professional.

\section{Implications}

An environment with both informal and formal support can lead adolescents to a better chance of seeking mental health help. Family friends and peer support are a crucial part of informal help that can encourage the adolescents to find acceptance, breaking free of personal barriers and the ability to reach out to seek help without the fear of negative outcomes and talking to mental health counsellors which are categorized as formal help. The counselors can assist them to understand their issues. Additionally, the presence of programs promoting awareness about mental health is very important as it increases the general literacy and awareness about mental health issues. The increase in awareness leads for the individual to have better-coping ability, resilience and the potential of positive engagement with the society. Hence this will also generate an overall positive outlook on life and success in an individual's specific roles in life.

\section{Ethics Approval and Consent to Participate}

Not applicable.

Human and Animal Rights

Not applicable.

\section{Consent for Publication}

Not applicable.

\section{Availability of Data and Materials}

None.

\section{FUNDING}


Biosight 2021; 02(02): 4-12

None.

\section{Conflict of Interest}

The authors declare no conflict of interest, financial or otherwise.

\section{Acknowledgements}

None.

\section{References}

1. S.L. Gray, C.L. Culpepper, D.P. Welsh. Encyclopedia of Human Behavior (Second Edition),Academic Press. 2012: 22-29,

2. Laski, Laura, and Expert Consultative Group for Every Woman Every Child on Adolescent Health. "Realising the health and wellbeing of adolescents." BMJ (Clinical research ed.) vol. 351 h4119. 14 Sep. 2015, doi:10.1136/bmj.h4119

3. Cummings, C. M., Caporino, N. E., \& Kendall, P. C. Comorbidity of anxiety and depression in children and adolescents: 20 years after. Psychological Bulletin. 2014; 140(3): 816-45.

4. Thapar, A., Collishaw, S., Pine, D., \& Thapar, A. Depression in adolescence. Lancet. 2012; 379(9820): 1056-67.

5. Benjamin L Hankin, Depression from childhood through adolescence: risk mechanisms across multiple systems and levels of analysis, Current Opinion in Psychology, Volume 4. 2015: 13-20, ISSN 2352-250X,

6. World Drug Report 2018 (United Nations publication, Sales No. E.18.XI.9).

7. Adams, S.H., Knopf, D.K., \& Park, M.J. Prevalence and Treatment of Mental Health and Substance Use Problems in the Early Emerging Adult Years in the United States: Findings from the 2010 National Survey on Drug Use and Health. Emerging Adulthood, (2). 2013: 163-72. Retrieved from http://eax.sagepub.com/content/2/3/163

8. United Nations Children's Fund (UNICEF). The State of the World's Children 2014 in Numbers: Every Child Counts, revealing disparities, advancing children's rights. New York: January 2014.

9. Abeid, M., Muganyizi, P., Olsson, P., Darj, E., Axemo, P. Community perceptions of rape and child sexual abuse: A qualitative study in rural Tanzania. BMC International Health and Human Rights. 2014; 14: 23.

10. WHO. Adolescents: health risks and solutions. Geneva: World Health Organization; 2018. Available from: http://www.who.int/en/news-room/fact-sheets/detail/adolescents-health-risks-andsolutions Accessed 09 May 2018

11. Rowe S, French R, Henderson C, Ougrin D, Slade M, Moran P. Help-seeking behavior and adolescent self-harm: a systematic review. Aust N Z J Psychiatry. 2014;48(12):1083-95.

12. World Health Organization (WHO). Global strategy on diet, physical activity and health. 2013.

13. World Health Organization. "Investing in mental health". Retrieved 29 June 2012.

14. Thornicroft G., et al. Undertreatment of people with major depressive disorder in 21 countries. Br J Psychiatry. 2017 Feb; 210(2):119-24.

15. Pescosolido, B. A., \& Lafsdottir, S. O. Beyond dichotomies: Confronting the complexity of how and why individuals come or do not come to mental health care. World J. Psychiatry (WPA). 2013; 12(3): 269-71. doi:10.1002/wps. 20072

16. Global and Cultural Mental Health. 2013. Retrieved from http://cimh.unimelb.edu.au/knowledge_translation_exchange/movement_for_global_mental_health/3r d mgmh summit/gbd 2010 and the comprehensive mental health action plan

17. Rickwood, D., Thomas, K., \& Bradford, S. Review of help-seeking measures in mental health: An Evidence Check rapid review brokered by the Sax Institute. 2012. https://www.saxinstitute. org.au/wpcontent/uploads/02_Help-seeking-measures-in-mentalhealth.pdf. Accessed 12 Oct 2017.

18. Salaheddin, K, and Barbara M. Identifying barriers to mental health help-seeking among young adults in the UK: a cross-sectional survey. J. R. Coll. Gen. Pract. 2016. vol. 66,651 e686-92. doi:10.3399/bjgp16X687313 
19. World Health Report. Shaping the future. Geneva, World Health Organization, 2003.

20. Mahmood A. Mental illness in Pakistan: The toll of neglect. Dawn [Internet]. 2014 Sep 20 [cited 2014 Sep 20]; Available from: https://www.dawn.com/news/1133196.

21. Zhu N, Allen E, Atun R. Lady health workers in Pakistan: improving access to health care for rural women and families. 2014. https://cdn2.sph.harvard.edu/wp-content/uploads/sites/32/2014/09/HSPHPakistan5.pdf

22. Humayun, A. Mental health priorities. 2016. November 19. Dawn. Retrieved from https://www.dawn.com/news/1297151

23. Shaikh, M.A. Bullying victimization among school-attending adolescents in Pakistan.. JPMA. J. Pak. Med. Assoc. 2013; 63(9): 1202.

24. Sultan, S. Perceived public stigma and attitude towards seeking Psychological help among Turkish and Pakistani people. Pak J Psychol. 2012; 43(1): 41-53

25. Ali A., Hassiotis A., Strydom A., King M. Self-stigma in people with intellectual disabilities and courtesy stigma in family carers: A systematic review. Research in Developmental Disabilities. 2012; 33 (6): 2122-40.

26. Gulliver A, Griffiths KM, Christensen H. Barriers and facilitators to mental health help-seeking for young elite athletes: a qualitative study. BMC Psychiatry. 2012: 12(1): 157

27. Clement S, Schauman O, Graham T, et al. What is the impact of mental health-related stigma on helpseeking? A systematic review of quantitative and qualitative studies. Psychol. Med. 2015; 45(1): 1127.

28. Ciftci, A., Jones, N., \& Corrigan, P. W. Mental health stigma in the Muslim community. J. Muslim Ment. Health. 2012; 7(1): 17-32.

29. Iftikhar B, Bashirullah N, Ishtiaq M, Subhan M, Khan SA. Perception and attitude of adolescents regarding adolescence related health issues in Peshawar Pakistan. J. Med. Sci. 2016; 24 (4): 241-46.

30. Ali, N., McLachlan, N., Kanwar, S., \& Randhawa, G. Pakistani young people's views on barriers to accessing mental health services. Int. J. Cult. Ment. 2017; 10(1): 33-43. doi:10.1080/17542863.2016.1248456

31. Hussain SS; Khan M; Gul R; Asad N. Integration of mental health into primary healthcare: perceptions of stakeholders in Pakistan. East Mediterr Health J. $2018.24(2): 146-153$. https://doi.org/10.26719/2018.24.2.146.

32. Ali, Tahir \& Gul, Sana. Community Mental Health Services in Pakistan: Review Study from Muslim World 2000-2015. PCH. Psychol. Comm. Health. 2018; 7: 57-71. 10.5964/pch. v7i1.224.

33. Tharani, A., Farooq, S., \& Naveed, A. Community mental health services: A way forward to rehabilitate chronic mentally ill client. J Ayub Med Coll Abbottabad. 2012; 24(2): 140-43.

34. Muhammad. Mental health most neglected field in Pakistan. 2012 October 9. thenews.com.pk. Retrieved March 30, from: http://www.thenews.com.pk/Todays-News-6-136490-Mental-health-most-neglectedfield-in-Pakistan

35. Irfan, M. Integration of mental health in primary care in Pakistan. J. Postgrad. Med. Inst. 2013; 27(4): 349-51.

36. Ali, G., Lalani, N. S., \& Charania, N. A. M. A. Community mental health initiatives in Pakistan. Nurs Stand. 2015; 29(22): 44-48. doi:10.7748/ns.29.22.44. e9250

37. Taj, R. Mental health in Pakistan. In D. Bhurga, S. Tse, R. Ng, \& N. Takei (Eds.), Routledge handbook of psychiatry in Asia. 2016: 101-14. London, United Kingdom: Routledge.

38. Lynch, L., Long, M., \& Moorhead, A. Young Men, Help-Seeking, and Mental Health Services: Exploring Barriers and Solutions. Am. J. Men's Health. 2018; 12(1): 138-49. http://doi.org/10.1177/1557988315619469

39. Jorm AF. Mental health literacy: empowering the community to take action for better mental health. Am. Psychol. 2012 Apr;67(3):231-43. doi: 10.1037/a0025957.

40. Li TM, Chau M, Wong PW, Lai ES, Yip PS. Evaluation of a Web-based social network electronic game in enhancing mental health literacy for young people. J Med Internet Res. 2013; 15(5): e80. doi: 10.2196/jmir.2316. http://www.jmir.org/2013/5/e80/ 